\title{
A review of prospective registration of trials published in nursing science journals in 2017
}

\section{Running head: Review of prospective trial registration}

Richard GRAY RN PhD1, 2, 3, George GRAY4 and Ellie BROWN DCounsPsych 5, 6, 7

1. School of Nursing and Midwifery, La Trobe University, Melbourne, Australia

2. Department of Rural Health, The University of South Australia, Adelaide, Australia

3. School of Nursing, The University of Essex, Colchester, Essex, UK

4. The Open University, Milton Keynes, UK

5. Orygen, The National Centre of Excellence in Youth Mental Health, 35 Poplar Road Parkville, Victoria 3052, Australia

6. Centre for Youth Mental Health, The University of Melbourne, 35 Poplar Road, Parkville, Victoria 3052, Australia

7. Deakin University, IMPACT Strategic Research Centre, School of Medicine, Geelong 3220, Australia

Acknowledgements: None

Author contribution: RG and EB conceived and designed the review. GG undertook title and full text screening, data extraction and prepared data tables. RG wrote the first draft of the paper. All authors contribute to revisions of the paper and approved the final version of the manuscript.

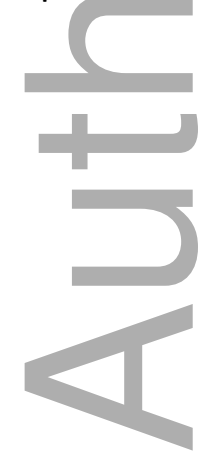

This is the author manuscript accepted for publication and has undergone full peer review but has not been through the copyediting, typesetting, pagination and proofreading process, which may lead to differences between this version and the Version of Record. Please cite this article as doi: $10.1111 /$ IAN.14131

This article is protected by copyright. All rights reserved 
PROFESSOR RICHARD JOHN GRAY (Orcid ID : 0000-0001-9694-4206)
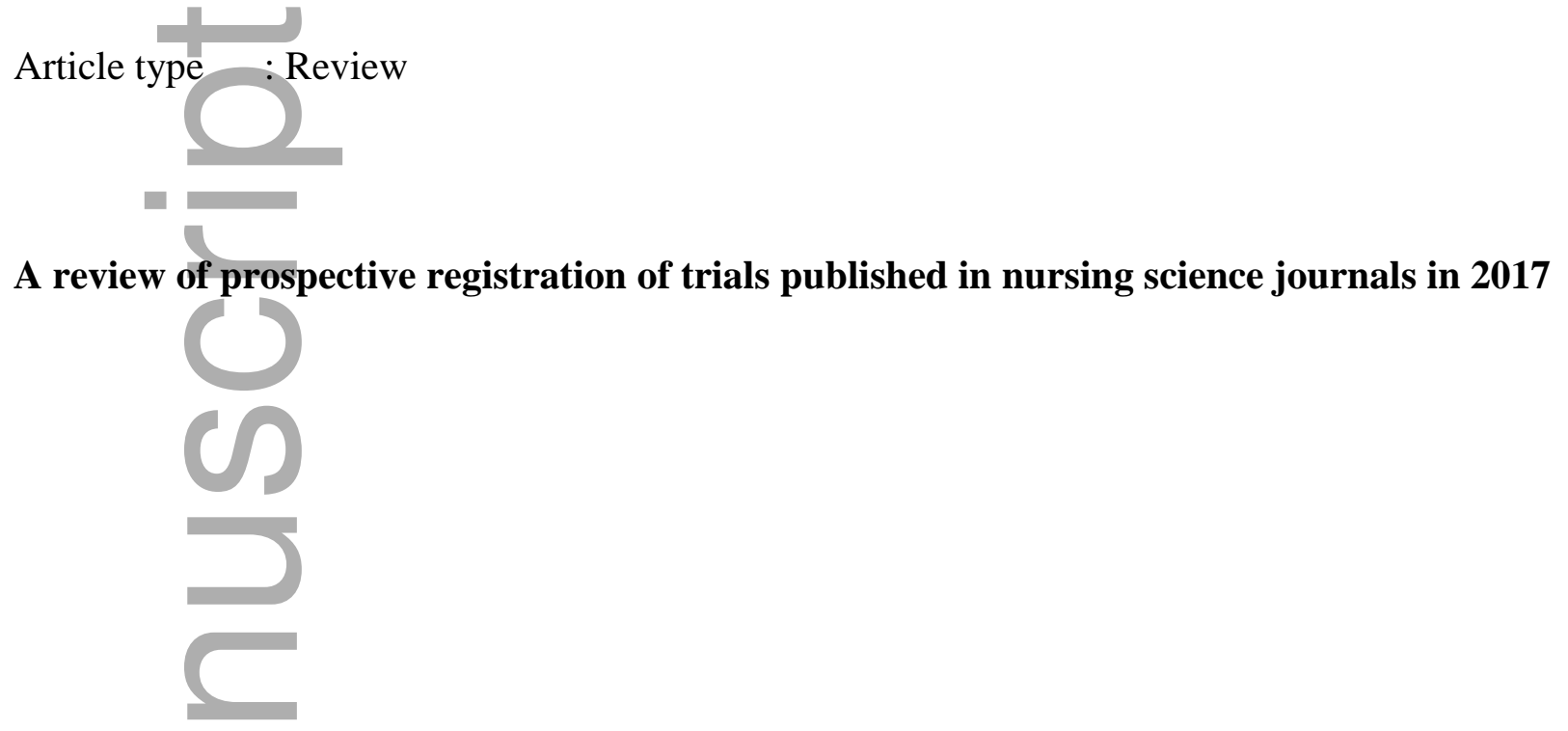

\section{Abstract}

Aim: To determine the proportion of trials published in nursing science journals in 2017 that were prospectively registered.

Design: A review of randomized controlled trials published in a Journal Citation Report nursing science journal in 2017.

Data source: Table of contents of included journals

Review methods: Randomized controlled trials were identified by manually reviewing the title of all papers published in included journals. Included trials were classified as: 1. Prospectively registered; 2. Retrospectively registered; 3. Registered but registration not reported in the manuscript; 5. Indeterminate registration; and 6. Not registered. Additionally, we recorded if the trial registration number was reported in the manuscript abstract.

Results: Of 151 randomized controlled trials published in nursing science journals in 2017, 17 (11\%) were prospectively registered. Thirty-six (24\%) trials were retrospectively and $93(62 \%)$ not registered. We could not determine the registration status of five (3\%) trials. The registration number was included in the abstract of two prospectively and eight retrospectively registered 
studies. Compared with the rest of the world, trial registration rates were significantly lower in Asian countries.

Conclusion: Two included trials were prospectively registered and reported a registration number in the abstract. Compared with other disciplines rates of prospective trial registration in are low. Nurse trialists must ensure that they prospectively register all trials.

Impact: We intended to replicate this review in subsequent years with a view to reporting improvements in prospective registration rates over time.

\section{Key words:}

randomised controlled trials, systematic reviews, nursing, trial registration

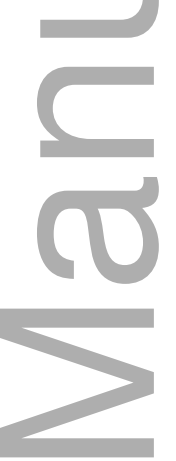

\section{INTRODUCTION}

A clinical trial is defined as "any research study that prospectively assigns human participants or groups of humans to one or more health-related interventions to evaluate the effects on health outcomes" (WHO, n.d.). Prospective trial registration creates a permanent, publicly accessible record. Registration is recognized as an important strategy to increase research transparency and accountability by minimizing publication and selective outcome reporting bias (Dickersin \& Rennie, 2003; Hunter, Seidler, \& Askie, 2018). Establishing the proportion of randomised controlled trials published nursing science journals that are prospectively registered sets a benchmark against which improvements over time can be measured.

\section{BACKGROUND}


In 2004 the ICMJE (International Committee of Medical Journal Editors) announced that they would not publish trials that started recruiting after 1 July 2005 that were not prospectively registered in a publicly accessible database (De Angelis et al., 2004). The Declaration of Helsinki - the cornerstone document guiding the ethical conduct of human subjects research states that "every clinical trial must be registered in a publicly accessible database before recruitment of the first participant" (World Medical Association, 2008). The World Health Organisation also considers trial registration to be a scientific, ethical and moral responsibility (WHO, n.d.).

The World Health Organisation has published a list of 17 trial registries that meet specific criteria for content, quality, validity, accessibility, unique identification, technical capacity and administration (http://www.who.int/ictrp/network/primary/en/). Registration entries include details of the intervention being tested, the comparator that will be used and intended outcomes of the trial.

Authors of a systematic review of trial registration in biomedical research identified 24 studies that included 5,529 RCTs (Trinquart, Dunn, \& Bourgeois, 2018). The pooled proportion of trials that were prospectively registered was $20 \%$, rates were higher in industry-funded and more extensive trials. An increase in prospective registration rates over time was reported, increasing from $25 \%$ in 2005 to $52 \%$ in 2015 . There was also some, albeit limited, evidence that registration rates were better in studies published in journals with a higher impact factor.

Gray et al., (2017) estimated the rates of trial registration in nursing science journals. The authors reviewed 135 RCTs published in the International Journal of Nursing Studies, the Journal of Advanced Nursing and the Journal of Psychiatric and Mental Health Nursing. Over a five-year period $24(18 \%)$ trials were prospectively registered.

Subsequent to the publication of this review the editors of four nursing journals (Journal of Psychiatric and Mental Health Nursing, Journal of Advanced Nursing, Journal of Clinical 
Nursing and Research in Gerontological Nursing) have published editorial guidance about trial registration (Gray, 2018; Kovach, 2019; Noyes, 2018; Smith et al., 2018). Gray (2018) report that the Journal of Psychiatric and Mental Health Nursing now "require" authors to register their trial. Noyes, (2018) states that trials published in the Journal of Advanced Nursing must be "prospectively registered." Smith et al., (2018) - who edit the Journal of Clinical Nursing - argue that "all nursing journal editors need to be explicit about the need for authors to register their trial" (p476). In an editorial in Research in Gerontological Nursing, Kovach, (2019) sets out the journal's editorial policy arguing that "registration [is required] of all intervention studies with randomization to study conditions that are not classified as pilot or feasibility studies" (p60).

\section{THE REVIEW}

\subsection{Aim}

This review aims to estimate the number of randomized controlled trials published in the Journal Citation Report (JCR) nursing science journals in 2017 that are prospectively registered.

\subsection{Design}

A review of randomized controlled trials published in the 110 English language "nursing science" journals listed in the 2016 Journal Citation Report was undertaken.

\subsection{Search methods}

Trials were identified by manually screening the title of papers published in 2017 for the phrase "randomized controlled" or "RCT" or "trial." Full texts of papers were then retrieved and checked against our inclusion and exclusion criteria. Both title and full-text screening were undertaken by a single researcher (GG).

\subsection{Search outcomes}


We included trials where the authors stated that participants were randomly allocated individually or as a group or cluster to at least two trial arms. Studies were excluded if: The first participant was enrolled before 2005 (i.e., before the ICMJE requirement for prospective registration). The paper was not written in English. The authors were reporting an extension or secondary analysis of an already published trial. Papers were "in press" or "accepted."

\subsection{Data extraction}

Data extraction was completed by GG and where there were queries, these were checked by the other authors. From included studies we extracted the following data: Study citation, funding, geographical region of corresponding author (using United Nations geoscheme), name of trial registry, trial registration number, reporting of registration number as part of the abstract, trials design (RCT, cluster RCT, stepped wedge, pilot/feasibility, other), sample size.

We checked that the trial registration number reported in the manuscript was correct and also extracted from the registry: trial registration date and date the first participant was enrolled in the trial. To ascertain if trials had been registered, but the registration number had not been reported in the published manuscript, we also manually searched three trial registries (clinicaltrials.gov, ISRCTN and ANZCTR) using keywords from the trial.

Some registries report the registration status (e.g. prospective/retrospective) of trials (e.g. ANZCTR), others (e.g. www.clinicaltrials.gov) do not. To determine if trials were prospectively registered we needed to confirm that registration preceded the start of the trial. There are some inconsistencies between the registries about how this information is recorded. In this study, we defined the date of trial registration as the date the registration number was issued (Gray et al. 2017). If this was not reported, then we used the date the author lodged their application with the trial registry as the proxy registration date. Where available, the actual trial start date was recorded; if this was not available, we used the anticipated start date. Using these data trials were classified into one of five groups (Gray et al., 2017):

1. Prospectively registered, before the first participant had been enrolled. 
2. Retrospectively registered, after the first participant had been enrolled

3. The trial was registered, but this was not reported in the manuscript

4. Not registered. No evidence, from any source, that the trial was registered.

5. Indeterminate registration status (where it was not possible to make a precise determination about the registrational status of a trial, for example, if an author reported a registration number, but no record could be found in the registry).

From the Journal Citation Report, we extracted journal impact factors and the total number of papers published in 2017. Journal author guidelines were reviewed (by GG) to determine if prospective/retrospective trial registration was a requirement of publication.

\subsection{Synthesis methods}

Descriptive statistics (means, standard deviation, proportions) were used to described the data. The Chi square statistic was used to test for associations between categorical data.

\section{Results}

The flow of trials through this review is shown in Figure 1. In total there were 8,266 papers published in journal citation report nursing science journals. We identified 151 papers (published in 50 different journals) that reported primary findings from RCTs, this represents $2 \%$ of all publications. A list of all included trials can be accessed via this link https://latrobe.figshare.com/s/70698023de6acf7a669b.

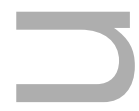

The results of our review are summarised in table 1. In 2017, two (1\%) RCTs published in nursing science journals met ICMJE criteria (i.e., Were prospectively registered, registration number incorporated in the abstract). Eleven percent of trials were prospectively registered and $24 \%$ retrospectively registered. Almost two thirds of trials were not registered. In ten trials (7\%) the authors reported the registration number in the abstract. 
The registration status of five included trials was indeterminate (Cao, Tian, Chen, \& Jiang, 2017; Cobbing, Hanass-Hancock, \& Myezwa, 2017; Jensen, Kiesbye, Soendergaard, Jensen, \& Kristensen, 2017; Salameh et al., 2017; Valiee, Razavi, Aghajani, \& Bashiri, 2017). When we checked the registration status of the Cobbing et al. (2017) trial, the registration number in the paper was not listed in the registry (South African National Clinical Trials Registry). The author was contacted. He agreed that the registration number we were using was correct and acknowledged it was not working. However, he also forwarded us correspondence from the registry evidencing that the trial had been registered. We did not contact the registry requesting further clarification. Cao et al. (2017) reported in their paper that they had registered the trial, but did not state which registry they had used. We wrote to the authors asking for this information, but they did not respond to our request. We checked the three registries (CTG, ANZCTRN, ISRCTN) to try and find the registration number but could not identify the trial. Finally, we could not determine if three trials were retrospectively or prospectively registered given the information that was in the papers and the registry (Salamah et al. 2017; Valiee et al. 2017; Jensen et al. 2017). One trial had two registration numbers (McCann, Songprakun, \& Stephenson, 2017), we wrote to the authors asking for clarification but did not get a response.

Most studies were RCTs; there were a small number of cluster and pilot/feasibility trials. A CONSORT flow diagram was reported in the manuscripts of around 8 out of 10 trials. The most commonly used trial registry was clinicaltrials.gov (17\%). Trials were registered on 11 registries of which ten were WHO recognized.

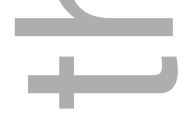

The authors of 98 included trials stated that their trial had received external funding. Post hoc we tested the association between funding and registration (prospective or retrospective) the association was significant (chi-square $=7.38, \mathrm{p}=.01$ ) perhaps suggesting that funded trials are more likely to be registered. 
The average number of participants randomized (sample size) in included studies was 137.95. The confidence intervals shown in Table 1 suggests there was no significant difference in sample sizes between prospectively, retrospectively, or unregistered trials.

Included papers were published in journals with a mean and median impact factor of 1.80 and 1.50 respectively. Confidence intervals shown in Table 1 do not suggest a significant difference in impact factor between trials with different registration status'.

In total 116 trials were published in journals where registration was mandated or inferred (i.e., authors should follow CONSORT guidelines), of these $13(11 \%)$ were prospectively registered. The remaining 35 trials were published in a journal where registration was not mandated or inferred, $4(11 \%)$ were prospectively registered an association that was not significant.

Half of the included trials were from authors based in Asia. The USA and Turkey were the two countries that published most trials (21 each). Post hoc we recoded trial registration status into two groups (registered/not registered). All geo-regions excluding Asia were also recoded into a single variable (rest of the world). We observed a significant association suggesting that rates of trial registration are significantly lower in Asian countries compared with the rest of the world (chi-square $=8.75, \mathrm{p}=.003$ ).

Table 2 shows a ladder of the number and proportion of trials prospectively, retrospectively and not registered by journal. All trials were prospectively registered in three journals (Journal of Korean Academy of Nursing, Holistic Nursing Practice and Nursing Research), noting each only published a single trial in 2017. The International Journal of Nursing Studies published more trials than any other journal. Of the 19 trials they published three (16\%) were prospectively registered.

\section{Discussion}

This article is protected by copyright. All rights reserved 
This review aimed to determine the proportion of RCTs published in nursing science journals in 2017 that were prospectively registered. Of 151 identified trials just 1 in 10 were prospectively registered. This rate is lower the previous studies in nursing where authors have selected specific journals (Gray et al., 2017). Compared with other clinical disciplines the numbers of prospectively registered trials is also low. For example, Trinquart et al., (2018) reported that in 2015 one in two biomedical trials were prospectively registered. Similarly, Huser \& Cimino (2013) reviewed 698 trials published in the five ICMJE founding journals (that includes the LANCET and British Medical Journal) they reported that $60 \%$ of trials met criteria for timely registration. It may be the journal editors and trialists have negative attitudes towards registration. Several authors have examined the trialists views, although none were explicitly in nursing. Reveiz, Krleža-Jerić, Chan, \& De Aguiar, (2007) surveyed the corresponding author of 500 PubMed listed clinical trials. The authors reported that while two-thirds of respondents supported trial registration, a third were unconvinced. A qualitative study of 13 medical journal editors views of trial registration exposed a reluctance to require registration in case they missed out publishing an otherwise accurate paper (Wager \& Williams, 2013). Some interviewees said that they did not feel that registration was necessary for smaller trials.

In our review, most registered trials were registered retrospectively. Trial registration intends to prevent selective publication and reporting of research outcomes. Retrospective registration addresses none of these. It may be argued that there is negligible value in retrospective registration. That said if journal editors mandate registration and ask authors to explain why they did not register their work prospectively this may help drive a culture change among nurse trialists. The editorial team at the Journal of Advanced Nursing are perhaps to be commended for enforcing retrospective registration (Noyes, 2018). Gray et al., (2017) reported that between 2011 and 2016 the Journal of Advanced Nursing published 42 trials of which two thirds ( $\mathrm{N}=28$, $67 \%$ ) were not registered. In this review only 1 of 6 of trials was not registered.

In this review, prospectively registered trials were not published in journals with a higher impact factor. This observation is not consistent with research in other clinical disciplines. Journal 
impact factor is often used as a proxy marker for research significance and rigor. It may be that in nursing science this assumption does not hold true.

As in the Gray et al., (2017) study, trials conducted in Asia were more significantly less likely to be registered. The consistency of this observation may suggest that there needs to be focused effort on increasing awareness about pre-registration of studies among nurse trialist from this part of the world.

One author, Gryder et al. (2017, p69), argued that their "study was designated as exempt from the FDA's requirements regarding an investigational new drug and trial registration requirements as a controlled clinical investigation." This does not seem to us to be a defendable position. As far as we can determine ICMJE guidelines do not exempt any particular trial design from registration.

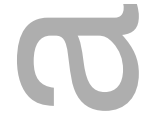

That so few papers reported the trial registration number as part of the abstract is slightly perplexing. The ICMJE clearly state that "journals [should] publish the trial registration number at the end of the abstract." Journal editors and publishers, may not be aware of this requirement and consequently do not enforce compliance.

\subsection{Review limitations}

There are limitations to our review that it is important to consider. Trials were identified by a single researcher manually searching individual journal websites. It is possible that some authors failed to state in the title that they were reporting an RCT and consequently we missed them when screening. We did initially test if we could do a keyword search of MEDLINE to identify RCTs, but this methodology proved unsuccessful. 
JCR nursing science journals, do not represent the totality of the nursing science literature. Many nursing science journals are not listed in the JCR and many nurse trialists do not publish in nursing journals. This is an acknowledged limitation of this review.

Only randomized studies were included in this review; we excluded controlled clinical trials and trials of any other design (e.g. before and after studies). It is a moot point about if these trials should be registered. While, in our opinion, they should - they meet the WHO definition of a clinical trial - we note some journal editors (Chyun, 2014; Kovach, 2019) have argued that registration is not necessary.

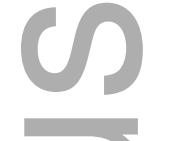

We did not check selective reporting bias, i.e., authors changed or amended outcomes. There would only be merit in doing this in prospectively registered trials and we felt that, while interesting, was outside of the scope of this review. Our review included only a modest number of trials. As a consequence, our study lacks adequate statistical power to detect factors that may predict prospective registration.

We used the corresponding author (that typically denotes senior author) to define the country where the research was undertaken. However, it was apparent when reviewing papers that fieldwork was sometimes undertaken in a different country to that of the corresponding author. For example, in the McCann et al., (2017) study the corresponding authors is based in Australia, but the fieldwork was seemingly undertaken in Thailand. It may have been more appropriate to extract information about where fieldwork was conducted directly from the manuscript. However, we note that in our experience this is not consistently reported.

We were unable to confirm if recruitment had started before 1st July 2005 for 18 studies. We decided to include these studies in our analysis. However, it is possible that fieldwork was conducted before 2005 and these trials should have been excluded. We did not contact authors to check when the trial started and this is perhaps an omission. 
Author guidelines were coded as inferring trial registration if they stated that authors should comply with CONSORT guidelines or ICMJE standards. This may have been overly generous. Question 23 of the CONSORT checklist relates to registration. However, in the accompanying explanation and elaboration paper, Moher et al. (2010, p21) only suggest that authors provide the name of the registry and registration number. We also coded papers in the International Journal of Nursing Studies and the Journal of Nursing Research as requiring registration when the guidelines, in fact, only suggest it.

\section{Conclusion}

Prospective clinical trial registration is generally acknowledged as best practice. Registrations is a comparative straightforward online process, see for example http://www.anzctr.org.au/ (authors clinic on the box marked "register your trial" and follow the instructions). Nursing science appears to lag behind other clinical disciplines. Funding bodies, study sponsors, journal editors and trialists all have an important role to play in improving prospective trial registration. We intend to repeat this review with trials published in 2018 (and again in subsequent years). It is our hope is that by headlining the number of trials in the disciple that are prospectively registered we raise awareness among colleagues and as a result, improving the quality of future nursing science.

\section{Funding Statement:}

This research received no specific grant from any funding agency in the public, commercial, or not-for-profit sectors.

\section{Conflict of interest:}

No conflict of interest has been declared by the authors.

\section{References}

Cao, X.-Y., Tian, L., Chen, L., \& Jiang, X.-L. (2017). Effects of a hospital-community partnership transitional program in patients with coronary heart disease in Chengdu, 
China: A randomized controlled trial. Japan Journal of Nursing Science, 14(4), 320-331. https://doi.org/10.1111/jjns.12160

Chyun, D. A. (2014). Registration of Nurse-Initiated Clinical Trials: Why, How, When? Nursing Research, 63(2), 73-74. https://doi.org/10.1097/NNR.0000000000000025

Cobbing, S., Hanass-Hancock, J., \& Myezwa, H. (2017). A Home-Based Rehabilitation Intervention for Adults Living With HIV: A Randomized Controlled Trial. The Journal of the Association of Nurses in AIDS Care: JANAC, 28(1), 105-117. https://doi.org/10.1016/j.jana.2016.08.008

De Angelis, C, Drazen, J. M., Frizelle, F. A. P., Haug, C., Hoey, J., Horton, R., ... Weyden, M. B. V.D. (2004). Clinical Trial Registration: A Statement from the International Committee of Medical Journal Editors. New England Journal of Medicine, 351(12), 1250-1251. https://doi.org/10.1056/NEJMe048225

Dickersin, K., \& Rennie, D. (2003). Registering clinical trials. JAMA, 290(4), 516-523. https://doi.org/10.1001/jama.290.4.516

Gray, R. (2018). Promoting openness and transparency in mental health nursing science. Journal of Psychiatric and Mental Health Nursing, 25(1), 1-2. https://doi.org/10.1111/jpm.12432

Gray, Richard, Badnapurkar, A., Hassanein, E., Thomas, D., Barguir, L., Baker, C., ... Topping, A. (2017). Registration of randomized controlled trials in nursing journals. Research Integrity and Peer Review, 2(1), 8. https://doi.org/10.1186/s41073-017-0036-9

Hunter, K. E., Seidler, A. L., \& Askie, L. M. (2018). Prospective registration trends, reasons for retrospective registration and mechanisms to increase prospective registration compliance: descriptive analysis and survey. BMJ Open, 8(3), e019983. https://doi.org/10.1136/bmjopen-2017-019983

Huser, V., \& Cimino, J. J. (2013). Evaluating adherence to the International Committee of Medical Journal Editors' policy of mandatory, timely clinical trial registration. Journal of the American Medical Informatics Association: JAMIA, 20(e1), e169-e174. https://doi.org/10.1136/amiajnl-2012-001501

Jensen, B. T., Kiesbye, B., Soendergaard, I., Jensen, J. B., \& Kristensen, S. A. (2017). Efficacy of preoperative uro-stoma education on self-efficacy after Radical Cystectomy; 
secondary outcome of a prospective randomized controlled trial. European Journal of Oncology Nursing, 28, 41-46. https://doi.org/10.1016/j.ejon.2017.03.001

Kovach, C. R. (2019). Should You Register Your Study as a Clinical Trial? Research in Gerontological Nursing, 12(2), 59-60. https://doi.org/10.3928/19404921-20190207-02

McCann, T. V., Songprakun, W., \& Stephenson, J. (2017). Effectiveness of a Guided Self-help Manual in Strengthening Resilience in People Diagnosed with Moderate Depression and Their Family Caregivers in Thailand: A Randomised Controlled Trial. Issues in Mental Health Nursing, 38(8), 655-662. https://doi.org/10.1080/01612840.2017.1313913

Noyes, J. (2018). Which studies should be registered on a clinical trials registry? Journal of Advanced Nursing, 74(11), 2479-2479. https://doi.org/10.1111/jan.13696

Reveiz, L., Krleža-Jerić, K., Chan, A.-W., \& De Aguiar, S. (2007). Do trialists endorse clinical trial registration? Survey of a Pubmed sample. Trials, 8, 30. https://doi.org/10.1186/17456215-8-30

Salameh, A. B., Al- sheyab, N., El- hneiti, M., Shaheen, A., Williams, L. M., \& Gallagher, R. (2017). Effectiveness of a 12-week school-based educational preventive programme on weight and fasting blood glucose in "at-risk" adolescents of type 2 diabetes mellitus: Randomized controlled trial. International Journal of Nursing Practice, 23(3), e12528. https://doi.org/10.1111/ijn.12528

Smith, G. D., Gelling, L., Haigh, C., Barnason, S., Allan, H., Penny, K., \& Jackson, D. (2018). Transparency in the reporting of nursing research. Journal of Clinical Nursing, 27(3-4), 475-477. https://doi.org/10.1111/jocn.14212

Trinquart, L., Dunn, A. G., \& Bourgeois, F. T. (2018). Registration of published randomized trials: a systematic review and meta-analysis. BMC Medicine, 16(1), 173. https://doi.org/10.1186/s12916-018-1168-6

Valiee, S., Razavi, N. S., Aghajani, M., \& Bashiri, Z. (2017). Effectiveness of a psychoeducation program on the quality of life in patients with coronary heart disease: A clinical trial. Applied Nursing Research: ANR, 33, 36-41. https://doi.org/10.1016/j.apnr.2016.09.002 
Wager, E., \& Williams, P. (2013). "Hardly worth the effort”? Medical journals' policies and their editors' and publishers' views on trial registration and publication bias: quantitative and qualitative study. BMJ, 347, f5248. https://doi.org/10.1136/bmj.f5248

WHO | Clinical trials. (n.d.). Retrieved 27 February 2017, from WHO website: http://www.who.int/topics/clinical_trials/en/

WHO | Trial Registration. (n.d.). Retrieved 6 March 2019, from WHO website: http://www.who.int/ictrp/trial_reg/en/

World Medical Association. (2008). Declaration of Helsinki: Ethical principles for medical research involving human subjects,.

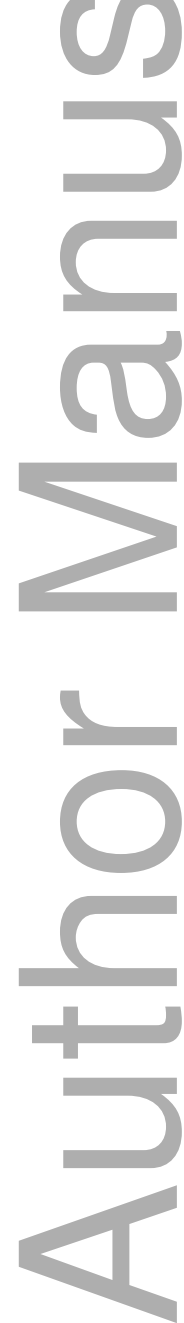

This article is protected by copyright. All rights reserved 
Table 1, results (summary of RCTs published in nursing science journals in 2017)

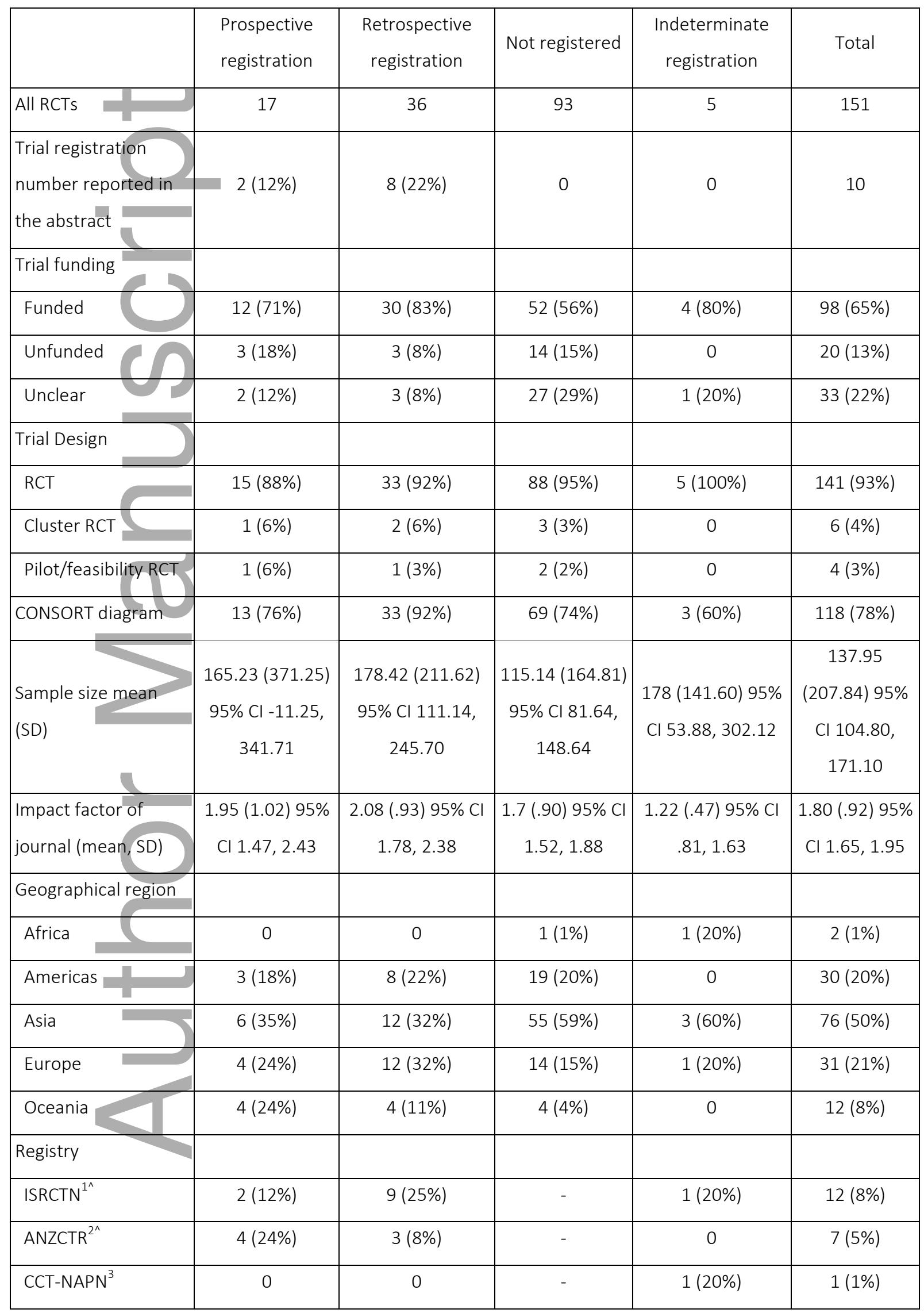




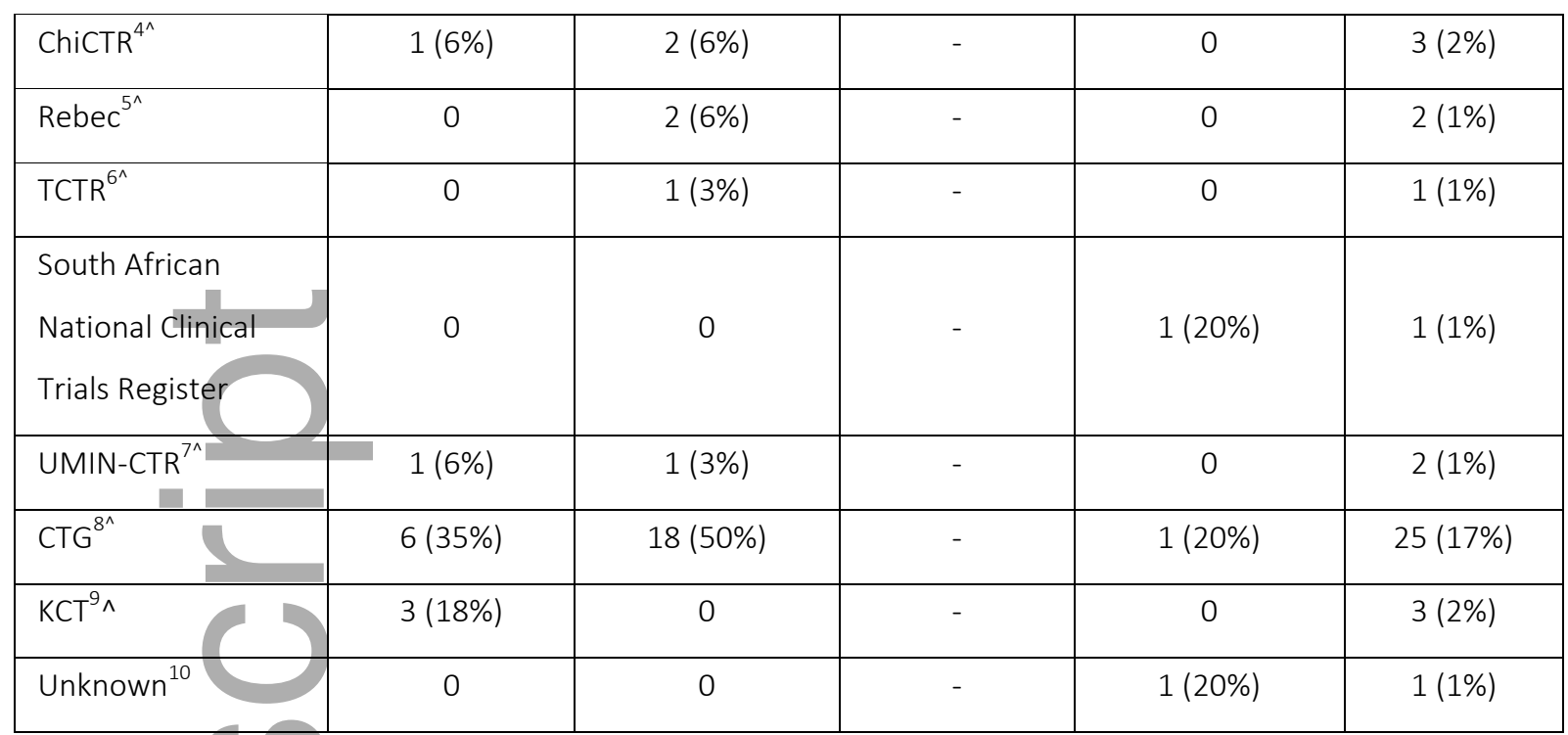

$\wedge$ World Health Organisation listed

1. ISRCTN

2. Australian New Zealand Clinical Trials Registry

3. Could not determine which registry the authors were referring to

4. Chinese Clinical Trials Registry

5. Registro Brasileiro de Ensaios Clinicos (Brazlian)

6. Thai Clinical Trial Registry

7. University Hospital Medical Information Network (Japanese)

8. www.clinicaltrials.gov

9. Clinical Research Information Service (Korean)

10. Authors state the trial was registered but did not indicate which registry was used and do not report a registration number

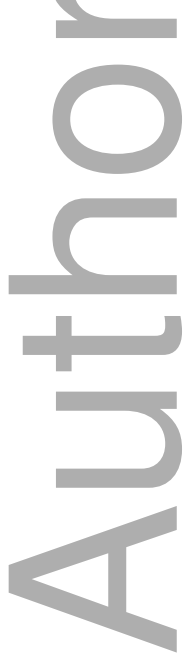


Table 2, ladder of included journals

\begin{tabular}{|c|c|c|c|c|c|c|}
\hline Rank & Journal name & $\begin{array}{l}\text { Number of } \\
\text { trials } \\
\text { published in } \\
2017\end{array}$ & $\begin{array}{l}\text { Prospectively } \\
\text { registered ( } \mathrm{n} \text {, } \\
\%)\end{array}$ & $\begin{array}{l}\text { Retrospectively } \\
\text { registered }(n, \%)\end{array}$ & $\begin{array}{c}\text { Not } \\
\text { registered } \\
(n, \%)\end{array}$ & $\begin{array}{l}\text { Indeterminate } \\
\text { registration }\end{array}$ \\
\hline$=1$ & $\begin{array}{l}\text { Journal of Korean } \\
\text { Academy of Nursing }\end{array}$ & 1 & $1(100 \%)$ & $0(0 \%)$ & $0(0 \%)$ & $0(0 \%)$ \\
\hline$=1$ & Holistic Nursing Practice & 1 & $1(100 \%)$ & $0(0 \%)$ & $0(0 \%)$ & $0(0 \%)$ \\
\hline$=1$ & Nursing Research & 1 & $1(100 \%)$ & $0(0 \%)$ & $0(0 \%)$ & $0(0 \%)$ \\
\hline 4 & $\begin{array}{l}\text { Journal of the Association } \\
\text { of Nurses in Aids Care }\end{array}$ & 2 & $1(50 \%)$ & $0(0 \%)$ & $0(0 \%)$ & $1(50 \%)$ \\
\hline$=5$ & Clinical Nursing Research & 2 & $1(50 \%)$ & $0(0 \%)$ & $1(50 \%)$ & $0(0 \%)$ \\
\hline$=5$ & $\begin{array}{l}\text { Journal of Paediatric } \\
\text { Health Care }\end{array}$ & 2 & $1(50 \%)$ & $0(0 \%)$ & $1(50 \%)$ & $0(0 \%)$ \\
\hline$=7$ & $\begin{array}{l}\text { Advances in Skin and } \\
\text { Wound Care }\end{array}$ & 2 & $1(50 \%)$ & $0(0 \%)$ & $1(50 \%)$ & $0(0 \%)$ \\
\hline$=7$ & $\begin{array}{l}\text { Nursing and Health } \\
\text { Sciences }\end{array}$ & 3 & $1(33 \%)$ & $1(33 \%)$ & $1(33 \%)$ & $0(0 \%)$ \\
\hline$=9$ & Cancer Nursing & 4 & $1(25 \%)$ & $0(0 \%)$ & $3(75 \%)$ & $0(0 \%)$ \\
\hline$=9$ & Midwifery & 4 & $1(25 \%)$ & $0(0 \%)$ & $3(75 \%)$ & $0(0 \%)$ \\
\hline 11 & $\begin{array}{l}\text { European Journal of } \\
\text { Cardiovascular Nursing }\end{array}$ & 5 & $1(20 \%)$ & $3(60 \%)$ & $1(20 \%)$ & $0(0 \%)$ \\
\hline 12 & $\begin{array}{l}\text { European Journal of } \\
\text { Cancer Care }\end{array}$ & 5 & $1(20 \%)$ & $1(20 \%)$ & $3(60 \%)$ & $0(0 \%)$ \\
\hline 13 & $\begin{array}{l}\text { European Journal of } \\
\text { Oncology Nursing }\end{array}$ & 5 & $1(20 \%)$ & $1(20 \%)$ & $3(60 \%)$ & $0(0 \%)$ \\
\hline 14 & $\begin{array}{l}\text { Journal of Cardiovascular } \\
\text { Nursing }\end{array}$ & 5 & $1(20 \%)$ & $0(0 \%)$ & $4(80 \%)$ & $0(0 \%)$ \\
\hline 15 & $\begin{array}{l}\text { International Journal of } \\
\text { Nursing Studies }\end{array}$ & 19 & $3(16 \%)$ & $6(32 \%)$ & $10(53 \%)$ & $0(0 \%)$ \\
\hline$=16$ & $\begin{array}{l}\text { Issues in Mental Health } \\
\text { Nursing }\end{array}$ & 2 & $0(0 \%)$ & $2(100 \%)$ & $0(0 \%)$ & $0(0 \%)$ \\
\hline$=16$ & Journal of Obstetric, & 1 & $0(0 \%)$ & $1(100 \%)$ & $0(0 \%)$ & $0(0 \%)$ \\
\hline
\end{tabular}




\begin{tabular}{|c|c|c|c|c|c|c|}
\hline & $\begin{array}{l}\text { Gynaecologic, \& Neonatal } \\
\text { Nursing }\end{array}$ & & & & & \\
\hline 18 & $\begin{array}{l}\text { Journal of Advanced } \\
\text { Nursing }\end{array}$ & 6 & $0(0 \%)$ & $5(83 \%)$ & $1(17 \%)$ & $0(0 \%)$ \\
\hline 19 & Women and Birth & 3 & $0(0 \%)$ & $2(67 \%)$ & $1(33 \%)$ & $0(0 \%)$ \\
\hline 20 & Nursing in critical care & 3 & $0(0 \%)$ & $2(50 \%)$ & $1(25 \%)$ & $1(25 \%)$ \\
\hline$=21$ & $\begin{array}{l}\text { Archives of Psychiatric } \\
\text { Nursing }\end{array}$ & 2 & $0(0 \%)$ & $1(50 \%)$ & $1(50 \%)$ & $0(0 \%)$ \\
\hline$=21$ & Biological Research for & 2 & $0(0 \%)$ & $1(50 \%)$ & $1(50 \%)$ & $0(0 \%)$ \\
\hline$=21$ & $\begin{array}{l}\text { International Journal of } \\
\text { Mental Health Nursing }\end{array}$ & 2 & $0(0 \%)$ & $1(50 \%)$ & $1(50 \%)$ & $0(0 \%)$ \\
\hline$=21$ & $\begin{array}{l}\text { Journal of Midwifery \& } \\
\text { Women's Health }\end{array}$ & 2 & $0(0 \%)$ & $1(50 \%)$ & $1(50 \%)$ & $0(0 \%)$ \\
\hline 25 & $\begin{array}{l}\text { Journal of Human } \\
\text { Lactation }\end{array}$ & 3 & $0(0 \%)$ & $1(33 \%)$ & $2(67 \%)$ & $0(0 \%)$ \\
\hline 26 & Nurse Education Today & 7 & $0(0 \%)$ & $2(29 \%)$ & $5(71 \%)$ & $0(0 \%)$ \\
\hline 27 & $\begin{array}{l}\text { Journal of peri-anaesthesia } \\
\text { Nursing }\end{array}$ & 4 & $0(0 \%)$ & $1(25 \%)$ & $3(75 \%)$ & $0(0 \%)$ \\
\hline 28 & Applied Nursing Research & 4 & $0(0 \%)$ & $1(20 \%)$ & $3(60 \%)$ & $1(20 \%)$ \\
\hline 29 & Journal of Clinical Nursing & 5 & $0(0 \%)$ & $1(20 \%)$ & 4 (80\%) & $0(0 \%)$ \\
\hline 30 & $\begin{array}{l}\text { Journal of Wound, Ostomy } \\
\text { and Continence Nursing }\end{array}$ & 6 & $0(0 \%)$ & $1(16 \%)$ & $5(83 \%)$ & $0(0 \%)$ \\
\hline 31 & $\begin{array}{l}\text { International Journal of } \\
\text { Nursing Practice }\end{array}$ & 7 & $0(0 \%)$ & $1(14 \%)$ & 5 (71\%) & 1 (14\%) \\
\hline 32 & $\begin{array}{l}\text { Japan Journal of Nursing } \\
\text { Science }\end{array}$ & 2 & $0(0 \%)$ & $0(0 \%)$ & 1 (50\%) & 1 (50\%) \\
\hline$=33$ & Asian Nursing Research & 3 & $0(0 \%)$ & $0(0 \%)$ & $3(100 \%)$ & $0(0 \%)$ \\
\hline$=33$ & $\begin{array}{l}\text { Journal of Paediatric } \\
\text { Nursing }\end{array}$ & 3 & $0(0 \%)$ & $0(0 \%)$ & $3(100 \%)$ & 0 (0\%) \\
\hline$=33$ & $\begin{array}{l}\text { Bariatric Surgical Practice } \\
\text { and patient care }\end{array}$ & 2 & $0(0 \%)$ & $0(0 \%)$ & $2(100 \%)$ & $0(0 \%)$ \\
\hline$=33$ & $\begin{array}{l}\text { Gastroenterology Nurses } \\
\text { and Associates. }\end{array}$ & 2 & $0(0 \%)$ & $0(0 \%)$ & $2(100 \%)$ & 0 (0\%) \\
\hline
\end{tabular}




\begin{tabular}{|c|c|c|c|c|c|c|}
\hline$=33$ & $\begin{array}{l}\text { Intensive and Critical Care } \\
\text { Nursing }\end{array}$ & 2 & $0(0 \%)$ & $0(0 \%)$ & $2(100 \%)$ & $0(0 \%)$ \\
\hline$=33$ & $\begin{array}{l}\text { The Journal of Nursing } \\
\text { Research }\end{array}$ & 2 & $0(0 \%)$ & $0(0 \%)$ & $2(100 \%)$ & $0(0 \%)$ \\
\hline$=33$ & Advances in Neonatal Care & 1 & $0(0 \%)$ & $0(0 \%)$ & $1(100 \%)$ & $0(0 \%)$ \\
\hline$=33$ & $\begin{array}{l}\text { Clinical Simulation in } \\
\text { Nursing }\end{array}$ & 1 & $0(0 \%)$ & $0(0 \%)$ & $1(100 \%)$ & $0(0 \%)$ \\
\hline$=33$ & $\begin{array}{l}\text { Computers, Informatics } \\
\text { and Nursing }\end{array}$ & 1 & $0(0 \%)$ & $0(0 \%)$ & $1(100 \%)$ & $0(0 \%)$ \\
\hline$=33$ & Geriatric & 1 & $0(0 \%)$ & $0(0 \%)$ & $1(100 \%)$ & $0(0 \%)$ \\
\hline$=33$ & Heart ar & 1 & $0(0 \%)$ & $0(0 \%)$ & $1(100 \%)$ & $0(0 \%)$ \\
\hline$=33$ & $\begin{array}{l}\text { Journal of Nursing } \\
\text { Scholarship }\end{array}$ & 1 & $0(0 \%)$ & $0(0 \%)$ & $1(100 \%)$ & $0(0 \%)$ \\
\hline$=33$ & $\begin{array}{l}\text { Journal of Perinatal and } \\
\text { Neonatal Nursing }\end{array}$ & 1 & $0(0 \%)$ & $0(0 \%)$ & $1(100 \%)$ & $0(0 \%)$ \\
\hline$=33$ & Nurse Educa & 1 & $0(0 \%)$ & $0(0 \%)$ & $1(100 \%)$ & $0(0 \%)$ \\
\hline$=33$ & Oncology nursing & 1 & $0(0 \%)$ & $0(0 \%)$ & $1(100 \%)$ & $0(0 \%)$ \\
\hline$=33$ & Orthopaedic Nursing & 1 & $0(0 \%)$ & $0(0 \%)$ & $1(100 \%)$ & $0(0 \%)$ \\
\hline$=33$ & $\begin{array}{l}\text { Research in Gerontological } \\
\text { Nursing }\end{array}$ & 1 & $0(0 \%)$ & $0(0 \%)$ & $1(100 \%)$ & $0(0 \%)$ \\
\hline$=33$ & $\begin{array}{l}\text { Worldviews on Evidence- } \\
\text { Based Nursing }\end{array}$ & 1 & $0(0 \%)$ & $0(0 \%)$ & $1(100 \%)$ & $0(0 \%)$ \\
\hline
\end{tabular}


Figure 1, Flow of trials through the review

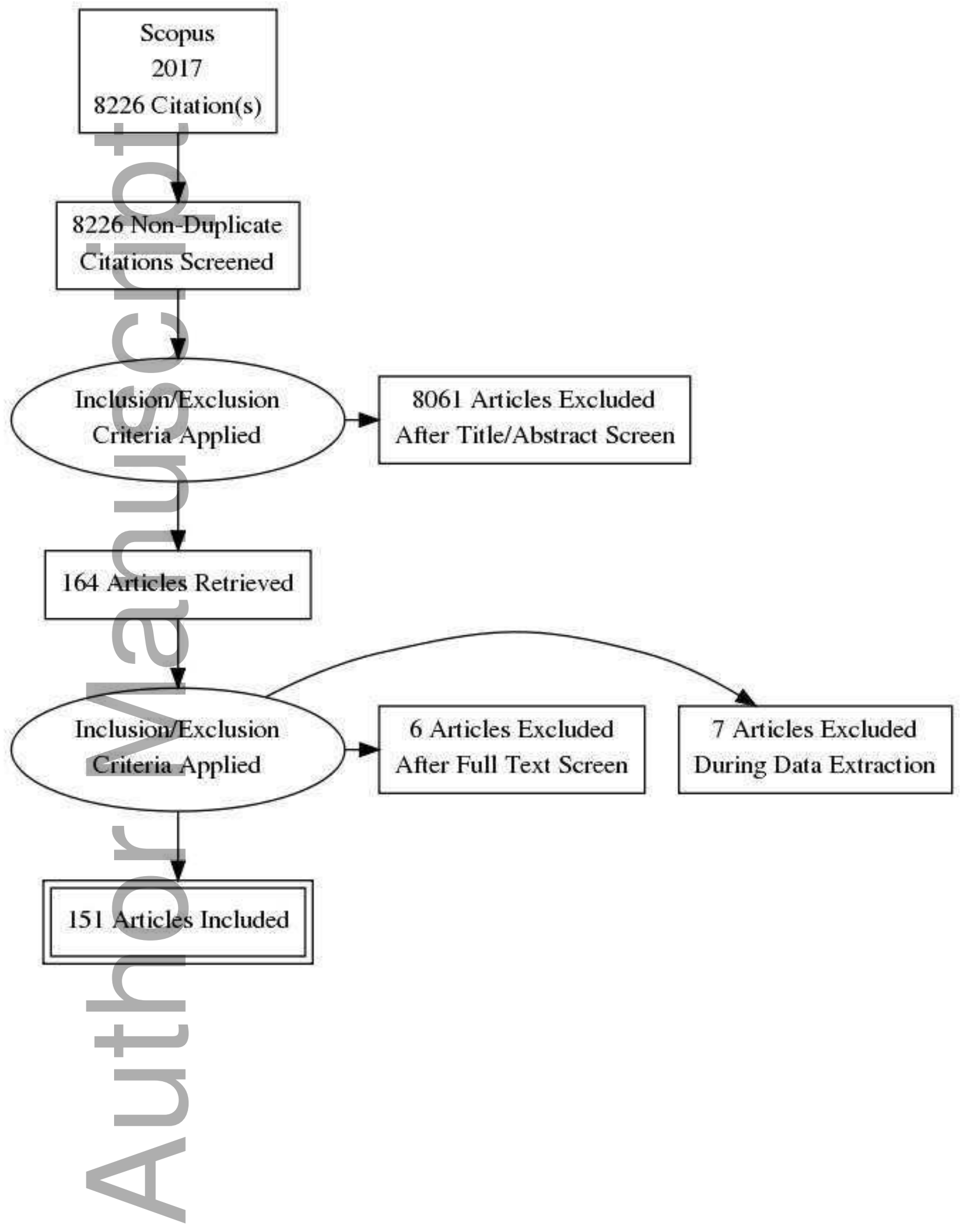

This article is protected by copyright. All rights reserved 


\section{University Library}

\section{- M M I N E R VA A gateway to Melbourne's research publications}

Minerva Access is the Institutional Repository of The University of Melbourne

Author/s:

Gray, R;Gray, G;Brown, E

Title:

A review of prospective registration of trials published in nursing science journals in 2017.

\section{Date:}

2019-12

Citation:

Gray, R., Gray, G. \& Brown, E. (2019). A review of prospective registration of trials published in nursing science journals in 2017.. J Adv Nurs, 75 (12), pp.3263-3271. https:// doi.org/10.1111/jan.14131.

Persistent Link:

http://hdl.handle.net/11343/286219 